\title{
Influence of fish-oil supplements on man
}

\section{By T. A. B. SANDers, Department of Nutrition, Queen Elizabeth College, University of London, Campden Hill Road, London $W 8{ }_{7} A H$}

Cod-liver oil has been used as a household remedy for centuries and over the course of time scientific explanations for its properties have become available. The first extensive clinical tests of cod-liver oil seem to have been made by Samuel Kay, a physician at the Manchester Infirmary from 1752 to 1784 . He gave doses of cod-liver oil to patients suffering from bone diseases and rheumatism and wrote 'the good effects of it are so well known among the poorer sort that it is particularly requested by them for almost every lameness'. Cod-liver oil played a central role in the isolation and discovery of vitamins $A$ and $D$ because it was known to cure night blindness, corneal xerosis and rickets. The nutritional value of cod-liver oil was officially acknowledged during World War II by the Ministry of Food who established a scheme for the free distribution of the oil to all infants up to 5 years old and to pregnant and nursing women. The issue of cod-liver oil by the Ministry of Food had a remarkable effect on the sales of the oil after the war. Indeed, the administration of cod-liver oil to children was widespread until the late 1950s. Cod-liver and halibut-liver oils still remain a popular supplementary source of vitamins $A$ and $D$. There has been renewed interest in fish-oil supplements since Dyerberg et al. (1978) postulated that dietary eicosapentaenoic acid (20:5 $\omega_{3}$; EPA) may offer protection against acute myocardial infarction by way of its influence on blood lipids, prostaglandins and haemostatic function.

Fish oil is a readily available source of EPA, consequently fish-oil supplements have been used to evaluate the effect of EPA on blood lipids, haemostasis and eicosanoid production. Different fish oils of varying composition and dose have been used so there are difficulties in extrapolating the results from one study to another. It should be emphasized that fish oils do contain other pharmacologically active ingredients apart from EPA. Most fish oils contain significant amounts of other $\omega_{3}$ polyunsaturated fatty acids such as docosahexaenoic acid $\left(22: 6 \omega_{3}\right.$; DHA), which shares several of the pharmacological effects of EPA (Corey et al. 1983 ), and so there is no justification in attributing all the effects observed with fish-oil supplements to EPA. The fatty acid composition of fish oil varies considerably from species to species and seasonally (Ackman, I982) and is dependent on the food chain. As a rule fish oils from cold-water fish contain high proportions of $\omega_{3}$ fatty acids, mainly EPA and DHA with smaller amounts of $18: 4 \omega_{3}$ and $22: 5 \omega_{3}$. The oils from certain tropical fish contain a relatively high proportion of arachidonic acid (20:4 $166 ; A A)$ (O'Dea \& Sinclair, 1982).

Generally, fish-liver oils contain high levels of vitamins $A$ and $D$, the highest concentrations being found in shark- and halibut-liver oil. Oils extracted from the crushed whole fish such as anchovy, sardine and menhaden oil contain far lower 
levels of the oil-soluble vitamins. All fish oils contain between 5 and $15 \%$ palmitoleic acid (16:1) and certain fish oils, such as mackerel, herring and salmon oils, contain substantial amounts of gadoleic (20:00II) and cetoleic (22:1011) acids, which are derived from the corresponding fatty alcohols produced by copopods.

$\mathrm{C}_{20-22}$ monoenes, like erucic acid (22:1 109$)$, are initially poorly oxidized and, when fed to experimental animals in large amounts, can lead to a transient myocardial lipidosis (Food and Agriculture Organization/World Health Organization, 1977; Cristopherson et al. 1982). Sardine, pilchard, anchovy and menhaden oils are low in $\mathrm{C}_{20-22}$ monoenes but contain high levels $(25-45 \%)$ of saturated fats, in particular myristic ( $14: 0$ ) and palmitic ( $16: 0$ ) acids. Many studies have used an oil blend called MaxEPA (Seven Seas Health Care, Hull) which has a standardized composition of $18 \%$ EPA and $12 \%$ DHA and is low in $\mathrm{C}_{20-22}$ monoenes and vitamins $A$ and $D$ but does contain $25-35 \%$ saturated fatty acids. Synthetic antioxidants and vitamin $\mathrm{E}$ are also added to MaxEPA in order to guard against lipid peroxidation.

The observation that Greenland Eskimos have the highest recorded intakes of fat (Bang \& Dyerberg, 1980) in the world yet have a low incidence of coronary heart disease (Kromann \& Green, I980) has considerably shaken the dietary fat hypothesis that a high intake of animal fat is the primary cause of coronary heart disease. It is uncertain whether this is because fish oil offers protection from atherosclerosis or because it reduces the severity of the complications of atherosclerosis, such as acute myocardial infarction and cerebral thrombosis.

\section{Influence of fish oils on plasma lipids}

High levels of low-density lipoprotein (LDL)-cholesterol, and very-low-density lipoprotein (VLDL)-triglycerides coupled with low levels of high-density lipoprotein (HDL)-cholesterol, especially that associated with the $\mathrm{HDL}_{2}$ fraction, are associated with the development of atherosclerosis (Havel, r 982). Hyperlipidaemia is also associated with high levels of certain clotting factors (Elkeles et al. 1980) and increased platelet reactivity (Stuart et al. 1980; Zahavi et al. 1981). Eskimos living on their traditional seafood diet, which provides approximately $5 \mathrm{~g} \mathrm{EPA}$ and $6 \mathrm{~g} \mathrm{DHA} / \mathrm{d}$, have high levels of HDL-cholesterol, moderately low levels of LDL cholesterol and very low levels of VLDL triglycerides compared with Eskimos living on a Western diet (Bang \& Dyerberg, 1980). It has been claimed that Eskimos are relatively free from atherosclerosis (Sinclair, r 980 ) but post-mortem studies on Canadian Eskimos, whose diets consisted of seal meat and fish, report the presence of atherosclerosis although less severe than expected for their age (Schaeffer, 1959).

Fish oils possess a cholesterol-lowering effect (Ahrens et al. 1959; Kingsbury et al. $196 \mathrm{I}$; Stansby, 1969$)$ that is attributed to their content of $\omega_{3}$ fatty acids and seems to result from a reduction in the proportion of cholesterol associated with both LDL and VLDL (Harris et al. 1983). This effect is only noted with high intakes in excess of about $8 \mathrm{~g} \mathrm{C}_{20-22} \omega_{3}$ fatty acids. LDL turnover studies have 
been carried out in subjects consuming in excess of $20 \mathrm{~g} \mathrm{C}_{20-22} \omega_{3}$ fatty acids and show a fall in the absolute synthetic rate of LDL and a slight fall in fractional catabolic rate (Illingworth et al. 1984). This is in contrast to studies with linoleic acid-rich vegetable oils which show an increase in fractional catabolic rate (Shepherd et al. 1980; Illingworth et al. 198I).

A slight increase in HDL-cholesterol concentration is seen in healthy subjects following the consumption of daily supplements of $20 \mathrm{ml}$ cod-liver or 10-20 $\mathrm{g}$ MaxEPA (Sanders et al. 1981; Sanders \& Hochland, 1983; Sanders \& Roshanai, 1983). This increase in HDL-cholesterol appears to be due to an increase in $\mathrm{HDL}_{3}$-cholesterol (Sanders \& Mistry, 1983; T. A. B. Sanders, K. Upton and M. Mistry, unpublished results) rather than the protective $\mathrm{HDL}_{2}$ fraction. Hepatic enzyme induction (Bolton et al. 1980) can increase HDL-cholesterol levels and it is pertinent that DHA induces hepatic monooxygenase (Van Rollins et al. 1984). HDL-cholesterol concentrations could also be increased by an increase in the enterohepatic circulation of bile acids.

Fish-oil supplements possess a plasma-triglyceride-lowering effect not shared by vegetable oils rich in either linoleic $(18: 2 \omega 6)$ or linolenic $\left(18: 3 \omega_{3}\right)$ acids (Sanders et al. 1981; Mortensen et al. 1983; Sanders \& Hochland, 1983; Sanders \& Roshanai, 1983) that is manifest at low doses. Sanders \& Roshanai (1983) showed that $10 \mathrm{~g}$ MaxEPA daily, but not lower doses, had a significant triglyceridelowering effect in normal subjects. Saynor (1984) and Simons et al. (1985), also using MaxEPA, reported a plasma triglyceride-lowering effect in hyperlipidaemic patients with 5 and $6 \mathrm{~g} / \mathrm{d}$ respectively of MaxEPA. Work with rats using purified ethyl esters has shown that both EPA and DHA possess this triglyceride-lowering effect (G. Kermode and T. A. B. Sanders, unpublished results).

Fish-oil supplements have a triglyceride-lowering effect of sufficient magnitude to be of therapeutic value in patients with primary hypertriglyceridaemia (Sanders \& Mistry, 1983; Sanders et al. 1985). Hypertriglyceridaemia results from an imbalance between the rate of produced triglyceride and its removal from the blood. An increased rate of clearance of triglyceride from plasma seems an unlikely explanation for the effect since $\mathrm{HDL}_{2}$-cholesterol concentrations do not increase, neither does the fractional rate of catabolism of VLDL change (Nestel et al. 1984; Sanders et al. 1985). There is a marked reduction in the absolute synthetic rate of VLDL-triglyceride (Nestel et al. 1984; Sanders et al. 1985) in hypertriglyceridaemic patients with fish-oil supplementation so the mechanism for this effect on triglyceride appears to be a decreased rate of hepatic triglyceride synthesis. A reduction in VLDL synthesis would in turn accelerate chylomicron clearance as a similar mechanism clears both VLDL and triglycerides from blood.

\section{Influence of fish oils on membrane lipids}

It is possible to cause substantial changes in polyunsaturated fatty acid composition of membrane phospholipids with fish-oil supplements (Sanders et al. 1981). The extent to which it is possible to modify platelet membrane composition with different types of $\omega_{3}$ fatty acids was studied by Sanders \& Younger (1981). 
Linseed-oil supplements providing $6.5 \mathrm{~g}$ linolenic acid taken daily for 2 weeks by healthy volunteers only led to a very small increase in the proportion of EPA but no change in that of 20:4 406 in platelet lipids. In contrast, $2.5 \mathrm{~g}$ preformed EPA/d as fish-oil concentrate (MaxEPA) led to a large increase in the proportion of EPA and a decrease in that of 20:4 $\omega 6$ in platelet lipids. Even intakes as low as I g EPA/d lead to a significant increase in the level of EPA in platelet phospholipids (Sanders $\&$ Roshanai, 1983 ). Changes in platelet lipid composition occur rapidly, usually within I week. So far no study using fish-oil supplements has produced changes in platelet lipid composition of the scale seen in Greenland Eskimos. This may be because the dietary intakes and body stores of linoleic acid of the experimental subjects are relatively high compared with Eskimos.

It is uncertain to what extent membrane composition must be altered in order to affect function. It has been suggested that it may be necessary to modify the fatty acid composition of specific lipid pools (Weiner \& Sprecher, I984), in particular that of phosphatidyl inositol (PI), in order to alter eicosanoid production. Fish-oil supplements do not appear markedly to alter the fatty acid composition of platelet PI: the changes that take place are mainly in the phosphatidyl ethanolamine and phosphatidyl choline fractions (Brox et al. 1981; Fischer \& Weber, 1983; Ahmed \& Holub, 1984). Cod-liver oil supplementation in addition leads to an increase in lignoceric acid (24:1) and a decrease in behenic acid $(22: 0)$ in platelet sphingomyelin (Ahmed \& Holub, 1984). Changes in membrane composition, besides influencing eicosanoid formation, may also influence membrane fluidity.

\section{Influence of fish oils on eicosanoid production}

As a general rule, the cyclo-oxygenase and lipoxygenase products of EPA are either inactive or less active compared with those derived from arachidonate. This led to the postulate that the replacement of AA with EPA would modulate the production of active eicosanoids (Moncada \& Vane, I979). There has, however, been considerable controversy as to whether prostaglandins and leukotrienes are formed from EPA in vivo. EPA is a poor substrate for platelet cyclo-oxygenase but is a good substrate, compared with AA, for the lipoxygenase (Gryglewski et al. 1979; Needleman et al. 1979; Hamberg, 1980) and so only small quantities of thromboxane $\mathrm{B}_{3}$ are formed (Fischer $\&$ Weber, 1984 ). Although the prostaglandin $\mathrm{PGI}_{3}$ is not formed in rats given fish oils (Hornstra et al. ${ }_{198 \mathrm{r}}$ ), its urinary metabolite has been detected by gas chromatography and mass spectroscopy in subjects given $40 \mathrm{ml}$ cod-liver oil daily for I week (Fischer \& Weber, 1983). Prescott ( $\left.198_{4}\right)$ has shown that leukotriene $B_{5}$ is formed in volunteers following the consumption of $40 \mathrm{ml} \mathrm{MaxEPA} / \mathrm{d}$ for 3 weeks. However, it remains to be shown whether these eicosanoids are formed in sufficient amounts to be of physiological significance.

The predominant effects of EPA and DHA on eicosanoid production are probably as inhibitors of linoleic acid and $A A$ metabolism: they readily displace $A A$ from membrane lipids and inhibit the conversion of linoleic acid to AA (Brenner \& Peluffo, 1967) and are competitive inhibitors for cyclo-oxygenase (Lands et al. 
I973; Hamberg, 1980; Corey et al. 1983). DHA is the major polyunsaturated fatty acid in some tissues such as the brain and there is a possibility that it plays an important role in down-regulating prostaglandin production in these tissues. Both EPA and DHA are potent inhibitors of human platelet aggregation in vitro (Gryglewski et al. 1979; T. A. B. Sanders and A. M. Lilburne, unpublished results) and several studies have noted a reduction in platelet thromboxane $B_{2}$ formation stimulated by collagen following the administration of fish-oil supplements (Brox et al. 1981; Fischer \& Weber, 1983; Sanders \& Hochland, 1983). Knapp \& Fitzgerald (1984) found a marked reduction in serum thromboxane $\mathrm{B}_{2}(>90 \%)$ but no change in the urinary metabolite of prostacyclin $\left(\mathrm{PGI}_{2}\right)$ with $40 \mathrm{ml}$ MaxEPA daily for 4 weeks. This implies that fish oil selectively decreases the formation of thromboxane $A_{2}$ from $A A$ in man.

\section{Prolongation of bleeding time}

Template bleeding time is prolonged by daily supplements of $20 \mathrm{ml}$ cod-liver-oil or MaxEPA-oil supplements (Sanders et al. 1980; Sanders \& Roshanai, 1983; Saynor et al. 1984). This is not accompanied by any change in the levels of clotting factors (Sanders et al. 1981) or by any marked inhibition of platelet aggregation induced by collagen or ADP (Goodnight et al. 1981; Sanders et al. 1981; Sanders $\&$ Roshanai, 1983). However, a slight increase in the threshold dose of collagen to result in aggregation has been noted (Brox et al. 1981 ; Hirai et al. 1982; Sanders $\&$ Hochland, 1983$)$. Moreover, reductions in $\beta$-thromboglobulin and platelet factor 4 , which are indicators of in vivo platelet aggregation, have been reported following the consumption of $20 \mathrm{ml}$ MaxEPA daily (Hay et al. 1982). It seems that the primary role of thromboxane $A_{2}$ is to cause vasoconstriction (Butler et al. I 982 ). Consequently the prolongation of bleeding time observed when fish oil is given could be a result of a decreased vasoconstrictor response to injury rather than impaired platelet plug formation. Thorngren (1983) argues against this because she was unable to demonstrate a reduction in the concentration of thromboxane $\mathrm{B}_{2}$ in blood emerging from bleeding time incisions of subjects with prolonged bleeding times following fish consumption. A reduction in whole-blood viscosity and an increase in erythrocyte deformability have been reported in individuals with low intakes of fish oil (Terano et al. 1983; Woodcock et al. 1984). The prolongation of template bleeding time represents an attenuated response to vascular injury. An attenuated response might mitigate the complications of atherosclerosis; indeed, studies with experimental animals (Black et al. 1979; Culp et al. 1980) have shown that fish-oil supplementation limits tissue damage following experimentally-induced ischaemia.

\section{Conclusion}

Moderate intakes of fish oil, providing 3-5 $\mathrm{g} \mathrm{C}_{20-22} \omega_{9}$ fatty acids/d (provided by $150-200 \mathrm{~g}$ oily fish), markedly lowered VLDL-triglyceride concentrations in plasma and led to a slight prolongation of template bleeding time. It remains to be shown whether the consumption of modest amounts of fish-oil supplements has any beneficial effects on morbidity and mortality from cardiovascular disease. 


\section{REFERENCES}

Ackman, R. G. (1982). In Nutritional Evaluation of Long-chain Fatty Acids in Fish Oil, pp. 25-88 [S. M. Barlow and M. E. Stansby, editors]. London: Academic Press.

Ahmed, A. A. \& Holub, B. J. (1984). Lipids 19, 617-624.

Ahrens, E. H., Insull, W., Hirsh, J., Stoffel, W., Peterson, M. L. \& Farquar, J. W. (1959). Lancet i, $115-116$.

Bang, H. O. \& Dyerberg J. (1980). In Advances in Nutrition Research, vol. 3, pp. 1-22 [H. H. Draper, editor]. New York: Plenum Press.

Black, K. L., Culp, B., Madison, D., Randall, O. S. \& Lands, W. E. M. (1979). Prostaglandins and Medicine 5, 257-268.

Bolton, C. H., Jackson, L., Roberts, C. J. C. \& Hartog, M. (1980). Clinical Science 58, 419-421.

Brenner, R. R. \& Peluffo, R. O. (1967). Biochimica et Biophysica Acta 137, 184-186.

Brox, J. H., Kille, J. E., Gunnes, S. \& Nordoy, A. (1 981 ). Thrombosis and Haemostasis (Stuttgart) 46, 604-6rir.

Butler, K. D., Maguire, E. D., Smith, J. R., Turnbull, A. A., Wallis, R. B. \& White, A. M. (1982). Thrombosis and Haemostasis (Stuttgart) 47, 46-82.

Corey, E. J., Shih, C. \& Cashman, J. R. ( 1983$)$. Proceedings of the National Academy of Sciences, USA 80, $35^{81} \mathrm{1}-35^{8} 4$.

Cristopherson B. O., Norseth, J., Thomassen, M. S., Christiansen, E. N., Norum, K. R., Osmundsen, H. \& Bremer, J. (1982). In Nutritional Evaluation of Long-chain Fatty Acids in Fish Oil, pp. 89-140 [S. M. Barlow and M. E. Stansby, editors]. New York: Academic Press.

Culp, B. R., Lands, W. E. M., Lucches, B. R., Pitt, R. \& Romson, J. (1980). Prostaglandins 20, $1021-1031$.

Dyerberg, J., Bang, H. O., Stofferson, E., Moncada, S. \& Vane J. R. (1978). Lancet i, 11 7-119.

Elkeles, R. S., Chakrabarti, R., Vickers, M., Stirling, Y. \& Meade, T. W. (1980). British Medical Journal 281, 973 .

Fischer, S. \& Weber, P. C. (1983). Biochemical Biophysical Research Communications r16, IOg I- I 099 .

Fischer, S. \& Weber, P. C. (1984). Nature 307, 165-168.

Food and Agriculture Organization/World Health Organization. (1977). Dietary Fats and Oils in Human Nutrition, A foint FAO/WHO Report, Rome: FAO.

Goodnight, S. H., Harris, W. S. \& Connor, W. E. (1981). Blood 58, 880-885.

Gryglewski, R. J., Salmon, J. A., Ubatuba, F. B., Weatherley, B. C., Moncada, S. \& Vane J. R. (1979). Prostaglandins $18,453^{-478}$.

Hamberg, M. (1980). Biochimica et Biophysica Acta 618, 389-398.

Harris, W. S., Connor, W. E. \& McMurry, M. P. (1983). Metabolism 32, 179-184.

Havel, R. J. (editor) (1982). Lipid Disorders. The Medical Clinics of North America, vol. 66. London: W. B. Saunders Co.

Hay, C. R. M., Durber, A. P. \& Saynor, R. (1982). Lancet i, 1269-1272.

Hirai, A., Terano, T., Hamazaki, T., Sajiki, J., Kondon, S., Ozawa, A., Fujita, T., Miyamoto, T., Tamura, Y. \& Kumagai, A. (1982). Thrombosis Research 28, 285-298.

Hornstra, G., Christ-Hazelhof, E., Haddeman, E., ten Hoor, F. \& Nugteren, D. H. (198I). Prostaglandins 21, 727-736.

Illingworth, D. R., Harris, W. S. \& Connor, W. E. (1984). Arteriosclerosis 4, 270-275.

Illingworth, D. R., Sundberg, E. E., Becker, N., Connor, W. E. \& Alaupovic, P. (1981). Arteriosclerosis 1,380 .

Kingsbury, K. J., Aylott, C., Morgan, D. M. \& Emmerson, R. (1961). Lancet i, 739-74 I.

Knapp, H. R. \& Fitzgerald, G. A. (1984). Symposium on n-3 Fatty Acids, July I 984 , University of Reading. Potters Bar: International Association of Fishmeal Manufacturers.

Kromann, N. \& Green, A. (1980). Acta Medica Scandinavica 208, 401-406.

Lands, W. E. M., LeTellier, P. R., Rome, L. H. \& Vanderhoek, J. Y. (1973). Advances in Bioscience 9, $15^{-28}$.

Moncada, S. \& Vane, J. R. (1979). New England Fournal of Medicine 300, I142-1 147.

Mortensen, J. Z., Schmidt, E. B., Nielsen, A. H. \& Dyerberg, J. (1983). Thrombosis and Haemostasis (Stuttgart) 50, 543-546. 
Needleman, P., Raz, A., Minkes, M. S, Ferrendelli, J. A. \& Sprecher, H. A. (1979). Proceedings of the National Academy of Sciences, USA 76, 944-948.

Nestel, P. J., Connor, W. E., Reardon, M. F., Connot, S., Wong, S. \& Boston, R. (1984). Fournal of Clinical Investigation 74, 82-89.

O'Dea, K. \& Sinclair, A. J. (1982). American Fournal of Clinical Nutrition 36, 868-872.

Prescott, S. M. (1984). Symposium on $n-3$ Fatty Acids, July 1984 , University of Reading. Potters Bar: International Association of Fishmeal Manufacturers.

Sanders, T. A. B. \& Hochland, M. (1983). British Fournal of Nutrition 50, $521-529$.

Sanders, T. A. B. \& Mistry, M. (1983). British Yournal of Clinical Practice 31, Suppl., 78-81.

Sanders, T. A. B., Naismith, D. J., Haines, A. P. \& Vickers, M. (1980). Lancet ii, 1 i 89.

Sanders, T. A. B. \& Roshanai, F. (1983). Clinical Science 64, $91-99$.

Sanders, T. A. B., Sullivan, D. R., Reeve, J. \& Thompson, G. R. (1985). Arteriosclerosis 5, (In the Press).

Sanders, T. A. B., Vickers, M. \& Haines, A. P. (1981). Clinical Science 61, 31 7-324.

Sanders, T. A. B. \& Younger, K. M. (1981). British Fournal of Nutrition 45, 61 $3^{-61} 6$.

Saynor, R. (1984). Lancet ii, 696 .

Saynor, R., Verel, D. \& Gillot, T. (1984). Atherosclerosis 50, 3-10.

Schaeffer, O. (1959). Canadian Medical Yournal 81, 386-393.

Shepherd, J., Packard, C. J., Grundy, S. M., Yeshururn, D., Gotto, A. M. \& Taunton, O. (I980). Fournal of Lipid Research $21,91-99$.

Simons, L. A., Hickie, J. B. \& Balasubramaniam, S. (1985). Atherosclerosis 54, 75-88.

Sinclair, H. M. (1980). In Drugs Affecting Lipid Metabolism, pp. 363-370 [R. Fumigalli, D. Kritchevsky and R. Paoletti, editors]. Amsterdam: Elsevier.

Stansby, M. E. (1 969). World Reveiw of Nutrition and Dietetics I 1, 46-405.

Stuart, M. J., Gerrard, J. M. \& White, J. G. (1980). New England Yournal of Medicine 302, 6-10.

Terano, T. Hirai, A., Hamazaki, T., Kobayashi, S., Fujita, T., Tamura, Y. \& Kumagai, A. L. (1983). Atherosclerosis 46, 321-331.

Thorngren, M. (1983). Dietary fish and haemostasis. Indications of antithrombotic properties. MD Thesis, University of Lund.

Van Rollins, M., Baker, R. C., Sprecher, H. W. \& Murphy, R. C. (1984). Fournal of Biological Chemistry 259, 5776- 5783 .

Weiner, T. W. \& Sprecher, H. (1984). Biochimica et Biophysica Acta 792, 293-303.

Woodcock, B. E., Smith, E., Lambert, W. H., Morris Jones, W., Galloway, J. H., Greaves, M. \& Preston, F. E. (1984). British Medical fournal 288, 592-594.

Zahavi, J., Betteridge, J. D., Jones, N. A. G., Galton, D. J. \& Kakkar, V. V. (1981). American Journal of Medicine 70, 59-64. 